\title{
Study of maternal and fetal outcome in eclampsia at Government Medical college, Aurangabad, Maharashtra, India
}

\author{
Rahulkumar S. Mahale ${ }^{1 *}$, Srinivas N. Gadappa ${ }^{2}$ \\ ${ }^{1}$ Department of Obstetrics and Gynecology, Swapnapurti Hospital, Mumbai, Maharashtra, India \\ ${ }^{2}$ Department of Obstetrics and Gynecology, GMC Aurangabad, Maharashtra, India
}

Received: 08 January 2019

Accepted: 07 February 2019

*Correspondence:

Dr. Rahulkumar S. Mahale,

E-mail: dr.rahulmahale@gmail.com

Copyright: (C) the author(s), publisher and licensee Medip Academy. This is an open-access article distributed under the terms of the Creative Commons Attribution Non-Commercial License, which permits unrestricted non-commercial use, distribution, and reproduction in any medium, provided the original work is properly cited.

\begin{abstract}
Background: Eclampsia is an obstetric enigma. Eclampsia as a clinical entity has been known from times immemorial. Even today it is one of the dreaded complications. Today also eclampsia is a life-threatening emergency that continues to be a major cause of serious maternal and perinatal morbidity and it's still the leading cause of maternal mortality in our country.

Methods: Method analysis of case records of all eclampsia cases from study period of October 2013 to September 2015, an observational study.

Results: The incidence of eclampsia was found to be $1.06 \%$ in GMC, Aurangabad. The number of maternal deaths of eclampsia patients was 7 out of 335 eclampsia cases. Maternal mortality in eclampsia patients was $2.08 \%$ in 2 -year study, however maternal mortality in hospital was $0.23 \%$ in 2 years study and the perinatal mortality rate in eclampsia was 361 per 1000 total births. while it is 84 per 1000 total birth for total deliveries in GMC Aurangabad during study. Majority of patients i.e. $87.75 \%$ were in the age group of $16-25$ years, $55.82 \%$ of total eclampsia were primigravida $57 \%$ eclampsia cases were referred from government or private hospitals, 11\% booked in GMC and 32\% patients were self. Antepartum eclampsia was the commonest type $82.11 \%$. 80\% patients of eclampsia were delivered vaginally and $18 \%$ underwent caesarean section ,2\% instrumental deliveries. $12 \%$ of babies had birth weight $1000 \mathrm{gm}$. $41 \%$ babies delivered with weight $2001 \mathrm{gm}$. Out of 264 live births 92 babies required NICU admission and 45 babies died in early neonatal period.

Conclusions: With good antenatal, intranatal and postnatal care with judicious use of anti-hypertensive, anticonvulsant and battery of investigations and judicious obstetric intervention, maternal and perinatal mortality can be reduced.
\end{abstract}

Keywords: Eclampsia, Maternal mortality, Perinatal mortality rate

\section{INTRODUCTION}

Eclampsia is one of the most dreaded complication of pregnancy and puerperium, is the principle cause of maternal morbidity and mortality in developing countries. Eclampsia has been defined as the occurrence of convulsion or coma, unrelated to other cerebral conditions in women with signs and symptoms of preeclampsia. ${ }^{1}$ It has been estimated that approximately
5000 women die each year worldwide from this dreaded disease. $^{2}$ A maternal mortality of $3 \%$ to $4 \%$ and perinatal mortality of $30 \%$ to $40 \%$ may occur following eclamptic convulsions. ${ }^{3}$ According to WHO report 2005, eclampsia still accounts for $12 \%$ of the maternal death throughout the world. ${ }^{4}$ In developed countries with good perinatal care facilities, or better facilities for case of preterm and low birth weight babies, very low fetomaternal morbidities and mortalities are reported. but in the 
developing countries, eclampsia is the 3rd most common cause of maternal mortality, after haemorrhage and infection. In India the maternal and perinatal morbidity and mortality due to eclampsia is very high. ${ }^{5-8}$ The figure of maternal mortality due to eclampsia ranges from 8 to $14 \%$ and perinatal mortality ranges from $14.6 \%$ to $17.4 \% .^{6,8}$ The incidence of eclampsia can be decreased with better antenatal care, early recognition of signs and symptoms and treatment of severe pre-eclampsia, but there are minority of patients in whom eclampsia may not be preventable as it comes like a "bolt from the blue", for these unfortunate patients and also for the ignorant patient authors can offer service and reduce both maternal and perinatal mortality due to eclampsia, rather than prevention of eclampsia The clinical management of eclampsia has gone through many changes and achieved a good result with introduction of different regime. One of the most significant development has been the recognition of the need for a multidisciplinary approach in the management of eclampsia and its complication. With the advent of imaging technologies like MRI in tertiary care centres, nowadays diagnosis of PRES is becoming common. So also enabling us to diagnose so called complicated eclampsia; i.e. eclampsia with HELLP, ARF, BIC, ICH etc. The present study is undertaken to analyse the maternal and fetal outcome in eclampsia in our institute. This study is carried out in government Medical College and Hospital, Aurangabad, which is tertiary care centre in an urban setting which caters to huge population including urban as well as rural. The hospital has large numbers of patients referred from urban health centre, primary health centre, rural hospital, subdistrict hospital, private hospitals and self.

The department of OBGY also introduced a new equipped eclampsia room just near the labour ward. That includes NST machine, ECG, Pulse Oxygen Monitor, emergency trolley, life support measure such as oxygen, suction machine multipara infusion pumps, neonatal incubator, and all emergency drugs. Also, operation theatre near that new eclampsia room for emergency LSCS and standard operational procedure (SOP's). With all the arrangements this study is undertaken to study the maternal mortality in antepartum, intrapartum and postpartum eclampsia.

\section{METHODS}

This study was carried out in Government Medical College, Aurangabad, which acts as an referral centre for both rural and urban population, all patients of eclampsia presented during the study period were included in the study. The total number of 335 cases of eclampsia patients admitted to the hospital from October 2013 to September 2015 were included in this study, after obtaining clearance from the hospital Ethical committee. The diagnosis of eclampsia was done by the obstetrics and gynaecology department of GMC based on the criteria led down by ACOG(American College of Obstetrics and Gynaecology).

\section{Inclusion criteria}

- Patient with antepartum convulsion

- Patient with intrapartum convulsion

- Patient with postpartum convulsion.

\section{Exclusion criteria}

- Patient with convulsion due to cause other than eclampsia like Epilepsy, CVT's, infection, trauma.

On Admission detailed history will be taken from the patient or her relative accompanying her and clinical examination will be done according to the proforma attached. If patient will be referred from outside, the details of treatment given also noted and treatment will be modified accordingly. At the time of admission all patient will be evaluated as per standard protocol. The following investigations will be done at the time of admission and repeated later as and when necessary. $\mathrm{Hb}$, WBC count, Platelet count, Prothrombin time, aPTT, Serum Bilirubin, Liver enzymes, Blood urea level, Serum creatinine level, Urine for Albumin and sugar and microscopy, Fundscopy. In addition, NST, Intrapartum fetal monitoring, abdominal as well as obstetric USG, CT. Scan, MRI will be done in certain patients as per individual needs.

\section{General measures}

- All patients will be admitted in a special isolated room equipped with a railed cot and facilities for suction, cardio pulmonary resuscitation oxygen and electronic foetal monitoring.

- Gentle nursing care including periodic oropharyngeal suction, maintenance of airway, nasal oxygen and strict antisepsis will be provided.

- Continuous monitoring of various parameters including pulse, blood pressure, and respiratory rate, level of consciousness, urine output and albumin and signs of development of other complications will be carried out in addition to routine obstetric monitoring.

- Intravenous fluids and antibiotics will be prescribed as per individual requirements.

- Appropriate laboratory investigation were carried out as per the requirements.

- Blood and blood products like fresh frozen plasma, platelets will be given to patients with coagulation abnormalities.

- Medical management: The agents used for treatment can be divided into:

- Anticonvulsants

- Antihypertensive

- Others.

- Obstetric Management.: Every patient will be evaluated at the time of admission and a suitable course of management will be adopted. Factors taken into consideration will be: 
- General condition of the mother

- Condition of the foetus

- Presence of signs of foetal jeopardy

- Past obstetric history of the patient.

- Any obstetric contraindication for vaginal delivery or of induction of labour.

The mode of delivery will be decided by the obstetric factors governing the individual patient during labour. Those patients who will be not in labour at the time of admission and with no contraindication for indication of labour will be induced with prostaglandin E2 or by intracervical Foley's catheter insertion or extra amniotic instillations of Ethacradine lactate. Active management of labour will be done in all the cases. Sweeping of membrane, amniottomy and augmentation with oxytocine will the techniques employed.

Caesarean section will be performed in many of the patient for various obstetric indications. The patients will keep under close observation in obstetrical intensive care unit for varying periods till their condition stabilized After delivery. This will be usually till about 24 hours post-partum after which they will be further followed up in wards till discharge. The babies who got shifted to NICU will be also followed up there till their discharge.

\section{RESULTS}

From October 2013 to September 2015 total 31,418 deliveries were conducted at GMC, Aurangabad.

During this study period there were 335 eclampsia cases. The incidence of eclampsia is $1.06 \%$ of total deliveries in the hospital during the study period (Table 1).

Table 1: Incidence of eclampsia.

\begin{tabular}{|l|l|}
\hline $\begin{array}{l}\text { Total number of deliveries during study } \\
\text { period }\end{array}$ & 31418 \\
\hline Total number of eclampsia cases & 335 \\
\hline Incidence & $1.06 \%$ \\
\hline
\end{tabular}

Majority of patients i.e. $87.75 \%$ were in the age group of 16-25 years and $2.68 \%$ were above 31 years of age (Table $2 \mathrm{a}$ and Table $2 \mathrm{~b}$ ).

Table 2a: Distribution of eclampsia cases on basis of their age.

\begin{tabular}{|l|l|l|}
\hline Age group (years) & Number of cases & $\%$ \\
\hline $16-20$ & 112 & 33.43 \\
\hline $21-25$ & 182 & 54.32 \\
\hline $26-30$ & 32 & 9.5 \\
\hline$>$ >30 & 09 & 2.68 \\
\hline
\end{tabular}

$55.82 \%$ of the total eclampsia patients were primigravida, followed by $10.33 \%$ in $2^{\text {nd }}$ and $3^{\text {rd }}$ gravid.
Table 2b: Distribution of eclampsia cases on basis of their age.

\begin{tabular}{|l|l|l|}
\hline Age & Number of cases & No. of pregnant women \\
\hline $16-25$ & 294 & 21758 \\
\hline $26->30$ & 41 & 9325 \\
\hline
\end{tabular}

$P$ value significance; According to Chia square test, $\chi^{2}=49.97$; $\mathrm{df}=1 ; \mathrm{P}$ value $=0.001$, df-Degree of differentiation .

Only $2.08 \%$ were in multigravida. There were $17.61 \%$ cases of post-partum eclampsia (Table 3).

Table 3: Distribution of eclampsia patients on basis of parity.

\begin{tabular}{|l|l|l|}
\hline Parity & No of cases & $\%$ \\
\hline G1 & 187 & 55.82 \\
\hline G2 & 51 & 15.22 \\
\hline G3 & 31 & 9.25 \\
\hline G4 & 07 & 2.08 \\
\hline PP & 59 & 17.61 \\
\hline Total & 335 & 100 \\
\hline
\end{tabular}

Majority of cases i.e. $67 \%$ of the total eclampsia cases did not receive antenatal care. $62 \%$ of total eclampsia patients were from rural area and $58 \%$ were from urban areas.

Table 4: Distribution of eclampsia patients on the basis of their referral status.

\begin{tabular}{|l|l|l|}
\hline Type & Number of patients & $\%$ \\
\hline Referrals & 192 & 57 \\
\hline Self & 108 & 32 \\
\hline Booked & 35 & 11 \\
\hline Total & 335 & 100 \\
\hline
\end{tabular}

Table 5: Distribution of cases on the basis of the type of eclampsia.

\begin{tabular}{|l|l|l|}
\hline Type & No. of cases & $\%$ \\
\hline Antepartum eclampsia & 275 & 82.11 \\
\hline Intrapartum eclampsia & 01 & 0.29 \\
\hline Postpartum eclampsia & 59 & 17.61 \\
\hline Total & 335 & 100 \\
\hline
\end{tabular}

Table 6a: Distribution of eclampsia patients on the basis of the gestation.

\begin{tabular}{|l|l|l|}
\hline Gestational age (weeks) & No. of cases & $\%$ \\
\hline$<28$ & 42 & 12.54 \\
\hline $29-32$ & 38 & 11.34 \\
\hline $33-36$ & 141 & 42.08 \\
\hline$>37$ & 55 & 16.42 \\
\hline Post-Partum & 59 & 17.62 \\
\hline Total & 335 & 100 \\
\hline
\end{tabular}

In the study of $90 \%$ patients were from lower socioeconomic status. $57 \%$ of total eclampsia cases were referred from Government enter or from private hospitals 
for further management. $11 \%$ patients were booked in our hospital and $32 \%$ patients were self.

$52 \%$ patients did not receive any Anti-consultant treatment, while $45 \%$ patients received inadequate dose inj. $\mathrm{MgSO}_{4}\left(\mathrm{H}_{2} \mathrm{O}\right)$ according to Pritchards regime and 3\% received adequate anti- consultant treatment.

Antepartum Eclampsia was the commonest type of eclampsia $82.11 \%$, followed by Post-partum eclampsia $17.61 \%$ and intrapartum eclampsia $0.29 \%$. $42.08 \%$ had convulsion between 33-36 weeks, followed by $17.62 \%$ of post-partum eclampsia $12.54 \%$ of eclampsia had convulsion at less than 28 weeks gestation (Table 4), (Table 5) (Table 6a and 6b).

Table 6b: Distribution of eclampsia cases according to the mean gestational age and standard deviation.

\begin{tabular}{l|l|l|l|} 
Mean & S.D. & Minimum Age & Maximum Age \\
\hline 34.49 & 3.8 & 16 & 40 \\
\hline
\end{tabular}
The mean gestational age was 34.49 weeks with a standard
deviation of 3.8 weeks.

Thus, eclampsia is more common in 34 weeks of gestation. In this study $38 \%$ of eclampsia patients had pre-monitary symptoms, $40 \%$ eclampsia patients had BP $\leq 140 / 90 \mathrm{~mm} \mathrm{Hg}$, 44\% had BP $140 / 91$ to $160 / 110 \mathrm{~mm} \mathrm{Hg}$ and $16 \%$ had $\mathrm{BP} \geq 161 / 110 \mathrm{~mm}$ of $\mathrm{Hg}$.

On Admission $90 \%$ had significant proteinuria, these shows that recording blood pressure and measurement of urine albumin both, simple procedure have great prognostic significant in prediction of morbidity and mortality in eclampsia.

$80 \%$ patients of eclampsia were delivered vaginally and $18 \%$ underwent caesarean section for various obstetric indications only $2 \%$ had instrumental deliveries (Table 7).

$72.19 \%$ patients had onset of convulsion to admission interval less than 5 hours while $26.55 \%$ had convulsion to admission interval between 6-20 hours.

Table 7: Distribution on the basis of the mode of delivery in eclampsia patients.

\begin{tabular}{|l|l|l|}
\hline Mode of delivery & No. of cases & $\%$ \\
\hline Vaginal & 265 & 80 \\
\hline LSCS & 63 & 18 \\
\hline Instrumental & 7 & 2 \\
\hline TOTAL & 335 & 100 \\
\hline
\end{tabular}

Group of patients with convulsion admission interval more than $20 \mathrm{hrs}$ included 2 patients. $68 \%$ patients had onset of convulsion on to delivery interval less than 12 hours. Only $1 \%$ patient had onset of convulsion to delivery interval for more than 24 hours. There were $18 \%$ patients of Post Partumeclampsia (Table 8).
Table 8: Distribution of eclampsia cases on the; onset of convulsion to delivery interval (in hours) in antepartum and intrapartum eclampsia patients.

\begin{tabular}{|l|l|l|}
\hline Time (in hours) & No. of cases & $\%$ \\
\hline$<5$ & 69 & 21 \\
\hline $6-12$ & 160 & 47 \\
\hline $13-24$ & 44 & 13 \\
\hline$>24$ & 03 & 1 \\
\hline PP & 59 & 18 \\
\hline Total & 335 & 100 \\
\hline
\end{tabular}

$12 \%$ of babies delivered to eclampsia patients had birth weight less than 1000 gms. $41 \%$ babies delivered to eclampsia patients had birth weight between 1001 to 2000 gms and $47 \%$ babies delivered to eclampsia patients had birth weight more than 2001 gms (Table 9a and 9b).

Table 9a: Distribution of new born's on the basis of their weight (in grams).

\begin{tabular}{|l|l|l|}
\hline Birth weight (grams) & No. of cases & $\%$ \\
\hline $501-1000$ & 41 & 12 \\
\hline $1001-1500$ & 57 & 17 \\
\hline $1501-2000$ & 85 & 24 \\
\hline $2001-2500$ & 108 & 32 \\
\hline$>2501$ & 49 & 15 \\
\hline Total & 340 & 100 \\
\hline
\end{tabular}

Table 9b: Mean birth weight and standard deviation.

\begin{tabular}{|l|l|l|l|}
\hline Mean & $\begin{array}{l}\text { Standard } \\
\text { deviation } \\
\text { (in grams) }\end{array}$ & $\begin{array}{l}\text { Minimum } \\
\text { weight }\end{array}$ & $\begin{array}{l}\text { Maximum } \\
\text { weight }\end{array}$ \\
\hline 1980 & 0.65 & 1 & 4 \\
\hline
\end{tabular}

Out of 264 live births of eclampsia Patients a total of 92 (34\%) babies required NICU admission.

During the study period of 2 years there were 335 deliveries and 340 babies were born, as there were 5 twin deliveries out of 340 babies; 264 were live births and 76 still births out of 264 live births 92 babies required NICU admission and 45 babies died in the early neo-natal Period (Table 10).

Table 10: Distribution on the babies of NICU admission in all live births of eclampsia patients.

\begin{tabular}{|l|l|l|}
\hline NICU admission & No. of cases & $\%$ \\
\hline Required & 92 & 34 \\
\hline Not required & 172 & 65 \\
\hline Total & 340 & 100 \\
\hline
\end{tabular}

The perinatal mortality rate in eclampsia patients was 361 per 1000 total live births and perinatal during rate of the hospital for 2 years study period 20 as 84 per 1000 live births. So, the perinatal mortality rate in eclampsia 
patients was 4.2 times the perinatal mortality among the total deliveries (Table 11a and 11b).

Table 11a: Distribution on the basis of perinatal outcome in eclampsia patients.

\begin{tabular}{|l|l|l|}
\hline Mortality rate & 340 & $\%$ \\
\hline Total births & 335 & 100 \\
\hline Total number of deliveries & 05 & \\
\hline $\begin{array}{l}\text { Total number of twin } \\
\text { deliveries }\end{array}$ & 264 & 77.64 \\
\hline Total live births & 76 & 22.35 \\
\hline Total still births & 45 & 17.04 \\
\hline Total neonatal deaths & 266 & 78.23 \\
\hline $\begin{array}{l}\text { Total premature deliveries } \\
\text { (<37 weeks) }\end{array}$ & $\begin{array}{l}361 \text { per } 1000 \\
\text { live birth }\end{array}$ & 36.1 \\
\hline $\begin{array}{l}\text { Perinatal mortality rate of } \\
\text { eclampsia patients }\end{array}$ &
\end{tabular}

Table 11b: Perinatal mortality rate.

\begin{tabular}{|l|l|l|}
\hline & $\begin{array}{l}\text { In eclampsia } \\
\text { patients }\end{array}$ & $\begin{array}{l}\text { In hospital during } \\
\text { study period }\end{array}$ \\
\hline Perinatal deaths & 121 & 2630 \\
\hline Total births & 335 & 31418 \\
\hline $\begin{array}{l}\text { Perinatal } \\
\text { mortality rate } \\
\text { (per } 1000 \text { total } \\
\text { birth) }\end{array}$ & $\begin{array}{l}361 \text { per } 1000 \\
\text { live birth i.e. } \\
(36.1 \%)\end{array}$ & $\begin{array}{l}\text { 84 per } 1000 \text { live } \\
\text { birth i.e. }(8.4 \%)\end{array}$ \\
\hline
\end{tabular}

In the hospital during study period. Birth Asphyxia, Hypothermia were the most common perinatal complication observed with $27.35 \%$ and $26.76 \%$ respectively. Other complication were prematurity $22.65 \%$, IUGR 22.05 , RDS $22.05 \%$, MAS $23.82 \%$, Septecemia $20.00 \%$ and ICH $13.23 \%$ (Table 12).

Table 12: Distribution of cases on the basis of fetal complication.

\begin{tabular}{|l|l|l|}
\hline Perinatal complication & No. of cases & $\%$ \\
\hline Prematurity & 77 & 22.64 \\
\hline IUGR & 75 & 22.05 \\
\hline Birth Asphyxia & 93 & 27.35 \\
\hline RDS & 75 & 22.05 \\
\hline MAS & 81 & 23.82 \\
\hline Septicemia & 68 & 20.00 \\
\hline Hypothermia & 91 & 26.76 \\
\hline ICH & 45 & 13.23 \\
\hline
\end{tabular}

Hypertensive crisis and PPH were most common complication observed i.e. $10.14 \%$ and $7.46 \%$ respectively.

While other complications seen were PRES Syndrome (5.97\%), Pulmonary oedema (5.67\%), DIC (5.07\%) HELLP syndrome $(4.17 \%)$ and Trauma $(6.8 \%)$.

Though the number of complications. $8 \%$ of all eclampsia patients were required to be managed in high dependency care unit which has ventilatory facilities, while $92 \%$ were managed at low dependency care unit with facilities for monitoring pulse rate, respiratory rate, blood pressure and oxygen saturation blood.

Table 13: Maternal complications.

\begin{tabular}{|c|c|c|c|}
\hline & Complications & No. of complications & $\%$ \\
\hline \multirow{4}{*}{ CNS } & Intracranial Hemorrhage & 02 & 0.59 \\
\hline & Cerebral Infarct & 04 & 1.19 \\
\hline & PRES Syndrome & 20 & 5.97 \\
\hline & Partial/Complete loss of Vision & 00 & 00 \\
\hline \multirow{3}{*}{ CVS } & Hypertensive Crisis & 34 & 10.14 \\
\hline & LVF & 00 & 0 \\
\hline & Arrhythmia & 00 & 0 \\
\hline \multirow{2}{*}{$\mathrm{RS}$} & Pulmonary Oedema & 19 & 5.67 \\
\hline & Aspiration Pneumonitis & 01 & 0.29 \\
\hline P/A-(liver) & HELLP Syndrome & 14 & 4.17 \\
\hline \multirow{3}{*}{ Hematological } & DIC & 17 & 5.07 \\
\hline & DVT & 00 & 0 \\
\hline & PPH & 25 & 7.46 \\
\hline Excretory system & ARF & 06 & 1.79 \\
\hline \multirow[t]{2}{*}{ Other } & Tongue Bite & 15 & 4.47 \\
\hline & Trauma & 8 & 2.38 \\
\hline
\end{tabular}

Out of 7 maternal deaths hypertensive crisis, DIC and HELLP syndrome were seen in all the cases. Pulmonary oedema and ARF were seen in 6 cases. Maternal mortality rate in eclampsia was 2089 per 1,00,000 live 
births in eclampsia patients. The maternal mortality rate of hospital during 2-year study period was 239 per $1,00,000$ live births.

So, the maternal mortality rate in eclampsia patients was approximately 9.04 times the maternal mortality among total deliveries in the hospital during study period (Table 14) (Table 15).

Table 14: Maternal mortality rate of eclampsia patients.

\begin{tabular}{|l|l|l|}
\hline Maternal Death & 7 & $\begin{array}{l}\text { In hospital during } \\
\text { study period }\end{array}$ \\
\hline Total live Birth & 335 & 75 \\
\hline Maternal mortality & $2.08 \%$ & 31418 \\
\hline
\end{tabular}

The number of maternal deaths of eclampsia patients was 7 out of 335 cases. Measuring maternal mortality accurately is difficult accept where comprehensive registration of death and of causes of death exist, elsewhere census, surveys or models have to be used to estimate the level of maternal mortality, hence authors have not calculated maternal mortality rate. However, percentage calculation were done.

Table 15: Causes of maternal mortality in eclampsia.

\begin{tabular}{|l|l|}
\hline Maternal mortality causes & No. of cases \\
\hline Eclamptic coma & 2 \\
\hline Intracranial hemorrhage & 2 \\
\hline Pulmonary Oedema & 2 \\
\hline Disseminated intravascular coagulation & 4 \\
\hline Acute renal failure & 3 \\
\hline Cerebral oedema (PRES)/encephalopathy & 2 \\
\hline Congestive cardiac failure/IHD & 2 \\
\hline Hypertensive crisis & 2 \\
\hline PPH & 3 \\
\hline HELLP syndrome & 3 \\
\hline
\end{tabular}

\section{DISCUSSION}

\section{Incidence}

According to present study the incidence of eclampsia reported in GMC hospital was 1.06\% which is much higher than that of developed countries like United Kingdom; where eclampsia complications are $0.05 \%$ of total deliveries. ${ }^{9}$ Incidence of eclampsia in other part of India as quoted by Suman Somegawda, was 3.72\% and Arupkumar Majhi et al was $2.79 \% .^{10,11}$

Incidence is higher because of poor antenatal coverage in rural areas with high referral rate. The incidence of eclampsia and total number of deaths from eclampsia have come down dramatically in developed countries. This has been achieved with improvement in prenatal care and early management of sever pre-eclampsia.

\section{Maternal age}

The maximum eclampsia patients were from 16-25 years of age i.e. $87.75 \%$ and mean age of patient was 22.76 years similar study results are shown by Arup Kumar Majhi et al and Chandrakant Jadhav study. ${ }^{11,12}$ So maximum patients among all eclampsia were below 25 years of age which indicates that young age is an important risk factor in developing eclampsia.

\section{Parity}

In present study 187 cases i.e. $55.82 \%$ were primigravida some studies like Baha Sibai is $87.36 \%$, Sardesai et al, $74.03 \%$ and Suman Somegauda et al, $77.24 \%$ have shown higher results. ${ }^{10,13,14}$

\section{Socio-economic status}

in this study most of the women $90 \%$ ie. 302 cases belong to lower socio-economic status according to Arup Kumar Majhi majority of the patients $82 \%$ belong to poor socioeconomic status which is largely related with health consciousness and health and family welfare of the people. ${ }^{11}$ This indicated that socioeconomic status , poor nutrition and inadequate antenatal care have close relationship with eclampsia.

\section{Antenatal care}

In this study majority of women i.e. $226(67 \%)$ did not receive antenatal care. So, maternal and perinatal mortality and morbidity in this group was higher. So, the result obtained in my study are comparable to Rupkumar Majhi et al $82.32 \%$, Sardesai et al $76.67 \%$ and Suman Somegauda is $94 \% .^{10,11,14}$ Hence it is an accepted norm that the incidence of eclampsia can be reduced by adequate antenatal care and early detection of preeclampsia and management.

\section{Hypertension and proteinuria}

In the present study 134 i.e. $40 \%$ of patients had mild hypertension i.e. Blood pressure and gt;140/90 $\mathrm{mm}$ of $\mathrm{Hg}$. 31 patients i.e. $10 \%$ had non-significant proteinuria. So according to Baha Sibai 32\% didn't have odema, 23\% had relative hypertension and $19 \%$ didn't have proteinuria at the time of convulsion. ${ }^{13}$ From present study authors can infer that even in the absence of either odema, hypertension, proteinuria and without any preceding premonitory symptoms and patient may still develop eclampsia. Dystolic BP above $110 \mathrm{~mm}$ of $\mathrm{Hg}$ was seen in $84 \%$ of cases with highest record of 210/130mm of $\mathrm{Hg}$. Higher the BP worst the prognosis.

\section{Types of eclampsia}

In my study that is majority of cases i.e. $225,82.11 \%$ were antepartum eclampsia. Similar results are shown by Baha Sibai i.e. 53\%, Suman Somegowda i.e. 90.95\%, K. 
Omkar Murty, Tumur i.e. 90\%. In postpartum eclampsia majority of patients develop convulsions within 24 hours except, 3 Patient developed on second day and 1 patient developed on the $5^{\text {th }}$ day. ${ }^{10,13,15}$ According to literature although postpartum eclampsia occurs up to 7 days after delivery, but there were very few cases after 48 hours.

\section{Gestational age}

In this present study 141 cases i.e. $42 \%$ of all eclampsia patients had conversions at the gestational age between 33 to 36 weeks. The mean gestational age was 34.49 weeks. Similar results were found in the study of $\mathrm{Dr}$ Chandrakant Jadhav, Maharashtra mean age 31.02\%. ${ }^{12}$

\section{Mode of delivery}

In this study there were $80 \%$ vaginal deliveries and $18 \%$ patients underwent caesarean section. These results are similar to those reported by Arupkumar Majhi i.e. Vaginal $89.48 \%$ and caesarean $10.50 \%$ and Sardesai et al i.e. vaginal $86.14 \%$ and caesarean $13.82 \% .^{11,14}$ There is no general agreement as to the mode of delivery in eclampsia reserving caesarean section only for obstetrical reasons. On the other hand, Pritchards and Pritchards, Chelsey have favored caesarean section to reduce maternal and perinatal mortality.

\section{Convulsion to admission}

The maternal and perinatal mortality rate increases when the interval between the $1^{\text {st }}$ convulsion and the admission in the hospital increases, due to delay in treatment to mother and prolonged exposure to intrapartum asphyxia. In this study maximum number i.e. 315 (92.19\%) of eclampsia patients have reached the hospital within 10 hrs. of onset of convulsion. Which is similar to Dr. Chandrakant Jadhav et al i.e. $85.18 \% .^{12}$

\section{Convulsion delivery interval}

In the present study $18 \%$ patients have post-partum convulsion. In this study maximum number of patients i.e. $68 \%$ had onset of convulsion to delivery interval less than 12 hours which was similar to Rajasri Yaliwal and Dr Prabhakar Gawandi studies i.e. $44.89 \%$ and $50.32 \%$ respectively. ${ }^{16,17}$ The perinatal mortality increases when the interval between the 1st convulsion and delivery increases due to prolong exposure to intrapartum asphyxia.

\section{Perinatal morbidity in eclampsia}

In the present study birth asphyxia was the common cause for increase in perinatal morbidity, whereas prematurity, IUGR, MAS, and RDS further added to the cause. All above conditions also increases the hospital stay of the patient and their babies. Out of 340 babies 76 (22.35\%) were still birth and $264(77.64 \%)$ were live births. In those 92 babies required NICU admission due to above perinatal morbidities. 45 babies out of 92 admitted in the NICU died due to above mentioned perinatal complications.

\section{Perinatal mortality rate}

Perinatal Mortality in this study was 361 per thousand live births which is comparable to study of Baha Sibai et al i.e. 118 per 1000 live births and Arup Kumar Majhi i.e. 399 per 1000 live births, J. Nadkarni Bahl i.e. 369 per 1000 live births, and Savita Rani Singhal, i.e. 367 per 1000 live births .It's a high value which shows that "Eclampsia still kills". ${ }^{11,13,18,19}$

\section{Maternal complication}

In my study pulmonary odema was found in $5.67 \%$ of total complication which is compared with other studies like Baha Sibai 13 4\%, Suman Somegowda 6.2\%, Savita Rani Singh $198 \% .^{10}$ Overall incidence of PRES was $0.7 \%$ in normal pregnancy and $6.5 \%$ in eclampsia in present study it shows $5.9 \%$. postpartum haemorrhage is $7.46 \%$ of total complication. It is found that the percentage is higher in other studies like Savita Rani Singh i.e.31\%. DIC (Disseminated Intravascular Coagulation) and HELP syndrome percentage were $5.0 \%$ and $4.17 \% .{ }^{19}$ which are comparable with the studies like Baha Sibai and Chandrakant Jadhav. ${ }^{12,13}$ Hypertensive crisis was the most common compared to other complications. This study is found similar to Adenkanle. ${ }^{20}$

\section{Maternal mortality}

In present study the maternal mortality was $2.08 \%$ where other comparative studies have higher readings like Arup Kumar Majhi et al $11.28 \%$, Sardesai et al $2.63 \%$, Suman Somegowda 5.44\%, Savita Rani Singhal et al $8 \%$ and DA Adenkanle $9.9 \% .^{10,11,14,20}$ Maternal mortality and prenatal loss are the yardstick for assessing the management of Eclampsia. The maternal mortality at our hospital in eclampsia cases was lesser than that reported by various studies. Direct comparison of results from different centers is impossible unless the severity of eclampsia, type, duration, number of convulsions and associated complications are known. The contribution of eclampsia in total maternal death is significant throughout the world. Another reason for decrease in maternal mortality and morbidity in our institute is because of the availability of 108 ambulance under the National Health Mission (NHM), which has encouraged early referral of patients to the hospital. Authors would also like to emphasize the importance of High Dependency Unit (HDU) as well as well-equipped eclampsia unit in our medical college that has helped tremendously to reduce the maternal mortality and morbidity. It has been estimated that 50,000 women die each year worldwide from this dreadful disease. A maternal mortality of 3 to 4 $\%$ and perinatal mortality of 30 to $40 \%$ may occur following eclamptic convulsions. According to the WHO 
report 2005, eclampsia still accounts you $12 \%$ of the maternal death, throughout the world.

In Hypertensive disorder of pregnancy, eclampsia is dreadful clinical endpoint along with pre-eclampsia syndrome entities. So, certainly the high incidence of eclampsia can be reduced by proper antenatal care, diagnosis, admitting and treating the mild and severe preeclampsia cases. High complication rates in countries with limited resources have sometimes been understood in the context of the three delays model. These delays include the delay in seeking medical care, delay in arriving at the facility, and delay at receiving standard care at the healthcare facility. Hence, eclampsia remains a continuing problem in developing countries and a leading cause of foetal and maternal mortality. As the study has shown, pregnant patients from low socio-economic group are also at a high risk of developing eclampsia. These patients do not get proper antenatal care though it is made available to them free of cost at all the government health care centres. Also, patients from rural areas and urban slums come to the health facility for ANC registration and immunization at early gestational age, the rest of pregnancy being unsupervised or under substandard care in the form of only inj. Tetanus Toxoid administered under ANC and many of them return to the health facility only after developing eclamptic convulsions. So, it is necessary to generate awareness in the population especially in rural and urban slum areas regarding regular antenatal visits in all the three trimesters of pregnancy, regarding availability of free antenatal care, and facilities for delivery at all government institutions. These pregnant patients should be given knowledge regarding the pre-monitory symptoms like headache, nausea, vomiting, blurring of vision and generalized oedema as danger signs and symptoms of preeclampsia and should be advised to seek the antenatal care at early stage for these symptoms during pregnancy. So, health education and public awareness regarding decision to seek care on time should be promoted at all the levels. With the advent of neuroimaging technology patients who had remained with uncontrolled hypertension and landed into PRES syndrome, are diagnosed earlier with CT-scan and more appropriately with MRI. PRES though a self-limiting syndrome, good prognosis can be achieved by antihypertensive, anticonvulsant and whenever required by mannitol. Another reason for decrease in maternal mortality and morbidity in our institute is because of the availability of 108 ambulance under the National Health Mission (NHM), which has encouraged early referral of patients to the hospital.

authors would also like to stress upon ANC care in all the trimesters, proper BP record and investigations to detect the disease before its manifestation. Most of the eclampsia patients presented with milder form of hypertension. Hence severity of the disease has to be taken into consideration irrespective of blood pressure records so, that the disease can be prevented. Maternal and perinatal outcome is good, if convulsion to delivery interval is less than 12 hours. Maximum cases who developed eclampsia were unbooked patients. It is

obvious from present study that out of 335 cases only 35 cases out of the booked cases developed eclampsia. This was because of the good maternal care, specially the BP records, investigations and obstetric interventions with $\mathrm{MgSO}_{4}$ and anti-hypertensive prophylaxis in sever preeclampsia. Early diagnosis and good perinatal supervision can prevent eclampsia to a large extent and appropriate treatment will ameliorate many cases sufficiently so that maternal care and fetal outcome is satisfactory. So, unless obstetric care is brought to the doorstep, no miracle can be expected. Clinical spectrum of preeclampsia is now preeclampsia syndrome which includes other complication related to each system to be CNS, CVS, RS, Kidney, GI and Blood.

This study is beyond scope of our topic; here authors recommend further study which will enlighten on preeclampsia syndrome. Pritchard regimen for treatment of eclampsia was found to be gold standard in present study and other regimen require further multicentric trial.

\section{CONCLUSION}

Present study shows that with good intranatal care and judicious use of antihypertensive, anticonvulsant and battery of investigation and judicious obstetric intervention, maternal and perinatal mortality can be reduced.

\section{Funding: No funding sources}

Conflict of interest: None declared

Ethical approval: The study was approved by the Institutional Ethics Committee

\section{REFERENCES}

1. Gabbe SG, Niebly JR, Simpson JL. Hypertension in pregnancy. In: Obstetrics -Normal and Problem pregnancies. New York :Churchill Livingstone, 1986:829-40

2. Duley L. Maternal mortality associated with hypertensive disorders of pregnancy in Africa, Asia, Latin America and the Caribbean. BJOG: Int J Obstet Gynaecol. 1992;99(7):547-53.

3. Davey D. A. Hypertension disorders of pregnancy Dewhurt's book of Obstetrics and Gynaecology. 5th edition Ed Charles R Whitefield P 182, Blackwell Science.

4. WHO The world health report 2005 ; Make every mother and child count Published by WHO Geneva WHO 2005.

5. Mudaliar AL Menon M K K .Toxemia of pregnancy in clinical obstetrics, orient longman ltd 1997 ;p13353.

6. Kameshwari Devi K, Sultana S, Santpur SR. Review of eclampsia cases (3369 cases). J Obstet Gynaecol India. 1976;26:53-8. 
7. Diekmann WJ. Blood chemistry and renal function in abortion placentae. Am J Obset Gynecol. 1936b; 31:734-44.

8. Weir RJ. Hypertension and eclampsia in pregnancy chapter 10 in practical obstetric problems. 5th edition Donald IA New Delhi, BL publication pvt ltd p 284 320.

9. Douglas KA, Redman CW. Eclampsia in United Kingdom. BMJ. 1994;309 (6966):1395-400.

10. Gaddi SS, Somegowda. Maternal and perinatal outcome in eclampsia in a district hospital. J Obst Gyn Ind. 2007:57(4):324-26

11. Majhi AK, Sanyal P, Chakraborty T, Ganguly, Mukherjee GG. Changing trends in maternal mortality in a teaching cum referral hospital. Obstel Gynecol India. 1996;46(3);345-53.

12. Jadhav C, Shinde M, Study of eclampsia at tertiary care center. Indian J Sci Res. 2015;4(6):411-3.

13. Sibai BM, Sarinoglu C, Mercer BM. Eclampsia: VII. Pregnancy outcome after eclampsia and long-term prognosis. Am J Obstet Gynecol. 1992;166(6):175763.

14. Sardesai SP, Patil A, Maira S, Patil U. Low dose magnesium sulphate therapy for eclampsia and imminent eclampsia: Regime tailored for Indian women. Int J Gynecol Obstet. 2000;70:B45-6.

15. Murthy KO, Shobha UN, Dhanajaya BS, Sameena Sultana S, A Comparative study of low dose magnesium sulphate regime and pritachard regime for imminent eclampsia and eclampsia. Int $\mathrm{J}$ Biol Med Res.2013;4(2):3001-4.

16. Yaliwal RG, Jaju PB, Vanishree M, Eclampsia and perinatal outcome: a retrospective study in a teaching hospital. J Clinic Diagnos Res. 2011;5(5):1056-9.

17. Gawandi P, Shinde MA, Jadhav CA Clinical. Study of eclampsia patients IOSR-JDMS. 2014;7(7):10-6.

18. Nodkarni J, Banl J, Parekh P: Perinatal outcome in Pregnancy Associated Hypertension. Indian. Pediat. 2001;38:174-8.

19. Singhal SR, Anshu D, Nanda S. Maternal and Preinantal outcome in severe Pre-Eclampsia and Eclampsia-South Asian Federation of Obstet Gynecol. 2009;1(3):25-8.

20. Adekanle DA, Akinbile TO. Eclampsia and pregnancy outcome at LAUTECH teaching hospital, Osogbo, SouthWest, Nigeria. Clinics in Mother and child health. 2012;9(1)

Cite this article as: Mahale RS, Gadappa SN. Study of maternal and fetal outcome in eclampsia at Government Medical college, Aurangabad, Maharashtra, India. Int J Reprod Contracept Obstet Gynecol 2019;8:932-40. 